\title{
Study on the Shear Strength of HMPE Fiber Reinforced Concrete
}

\author{
Hsien Hua Lee ${ }^{1, a}$ and C.-K. Juan ${ }^{1}$ \\ ${ }^{1}$ Department of Marine Environment and Engineering, National Sun Yat-sen University, Kaohsiung, \\ Taiwan \\ a email: hhlee@mail.nsysu.edu.tw
}

Keywords: Shear Strength, Fiber Reinforced Concrete, HMPE Fiber, Advanced Concrete Material

\begin{abstract}
Concrete as a most popular construction material has many advantages such as easiness to be formed into various shapes, common availability and relative low cost. However, the low strength in both tension and shear is limited for the wider application of the material. In this study, an advanced material of high strength and strong abrasion resistance HMPE fiber was used to reinforce concrete properties. A series of experimental testing were carried out to examine the properties of both fresh and hardened HMPE fiber reinforced concrete. It was found that the addition of an HMPE fiber material in concrete may enhance its shear strength as high as $30 \%$ increment. Corresponding to the increase of length of fiber entrained in the concrete, a slightly decreasing trend in shear strength was observed.
\end{abstract}

\section{Introduction}

Concrete as a construction material has many advantages such as easiness to be formed into various shapes, easiness in transportation, common availability and relative low cost. Nowadays concrete has become a material that is mostly applied to construction works. However, the shear strength of concrete material is low and in most cases it is $80 \%$ less than the compression strength. To overcome this problem, a steel reinforcement is integrated into the concrete material and become a well known nowadays the reinforced concrete. A fiber-form reinforcement added to the concrete is a common practice. Even though this practice can be categorized into a general form of reinforced concrete, it is generally termed as fiber reinforced concrete or FRC.

Actually, in the early age before the invention of fiber reinforced concrete material, it was very common that people utilized the fiber material such as weeds or split bamboo to reinforce the strength of a mud or cementicious material in construction works. Now many kinds of fibers have been applied to concrete material in order to improve the ductility and tensile properties of the material. The most popular fiber applied to concrete is steel fiber since it is a natural thought directly from the steel reinforcement for the RC material. The application of steel fibers can be categorized into regular arrayed fibers and randomly arrayed fibers. For the other fibers applied to FRC, the ratio of fiber to the concrete volume and the homogeneousness of fibers reinforced in the concrete becomes more important.

The study of steel fibers applied to concrete was firstly evoked by the improvement for the cracking behavior of plain concrete in 1960s. A high strength steel fibers was integrated into concrete to improve the flexural strength and brittleness of concrete material in 1980 [7], where various volumes in proportion to the concrete were added into concrete and analysis was performed. It was found that the addition of steel fibers to the concrete might effectively enhance both the strength and the ductility for the concrete material [5]. The abrasion resistance of concrete material was also found to be enhanced by the steel fibers added in the material [1].

The other fibers applied to enhancing properties of concrete material include fiberglass, polycarbonate fibers, nylon fibers, $\mathrm{PE}$ fibers and many other trials [2,8]. High-modulus polyethylene (HMPE) or high-performance polyethylene (HPPE) is a subset of the thermoplastic polyethylene. HMPE has extremely long chains, with molecular weight numbering in the millions that makes it a material with high strength and tough resistance to corrosion and abrasion [3]. Therefore, it was utilized in many applications such as the ballistic vests, high strength ropes and sport gadgets. In a previous study [6], some basic properties of fresh mixture and compressive 
strength of concrete reinforced with HMPE fibers were experimentally investigated and more than $20 \%$ increase in compressive strength was found.

However, studies on the shear behavior of concrete reinforced with fiber reinforcement is rare [4] and therefore, it is the purpose of this study to find the enhancement effect on the shear strength of concrete reinforced with HMPE fibers.

\section{Testing Plan and Set-up for Material Specimens}

In order to understand parameters that may influence the properties of the concrete reinforced with HMPE fibers, experimental testing was performed for both fresh and hardened concrete. For the properties of fresh concrete mixtures, basic testing for setting time based on ASTM C and slump test (ASTM C143) were performed. As for the hardened properties of concrete, in addition to shear strength test, compressive strength based on ASTM C39 was also examined. The compounds and proportions of the HMPE fiber reinforced concrete specimens are as follows.

HMPE Fibers. In this study the HMPE material is supplied by industry, of which the strength is $32 \mathrm{~g} / \mathrm{den}$ and the specific gravity is 0.97 .

Proportioning Design for Testing Samples. In the proportioning design of the FRC material, basic materials for traditional concrete were used such as Type I cement, fine aggregate and course aggregate. Except for the HMPE fibers, the side-product from the cast iron production blast furnace slag was also used to reduce the cement usage.

Proportions of Material. The ratio of water to binding material (w/b) for the testing group is 0.42. The proportion among cement, blast furnace slag, water, fine aggregate and coarse aggregate are $444\left(\mathrm{~kg} / \mathrm{m}^{3}\right), 148\left(\mathrm{~kg} / \mathrm{m}^{3}\right), 248.8\left(\mathrm{~kg} / \mathrm{m}^{3}\right), 646\left(\mathrm{~kg} / \mathrm{m}^{3}\right)$ and $807\left(\mathrm{~kg} / \mathrm{m}^{3}\right)$ respectively. Parameters of HMPE fibers under examination in the test is the length of the fiber while the volume ratio to a unit volume of concrete is set constant as $1.5 \%$. The variation of the fiber length is $20 \mathrm{~mm}, 40 \mathrm{~mm}$ and $60 \mathrm{~mm}$ corresponding to testing groups marked as HFRC2, HFRC4 and HFRC6 and the reference group without any fiber entrainment is labeled as HFRC0.

Shear Strength Testing. For the shear strength testing, due to the lack of standard testing facility and procedure, a test method for the pure shear strength of fiber reinforced concrete [4] was adopted. A similar testing facility with two angle-cranks supporting the tips of a panel specimen subjected to compression was built and set up in a structural testing laboratory in NSYSU, Taiwan. A schematic drawing is shown in Fig.1.

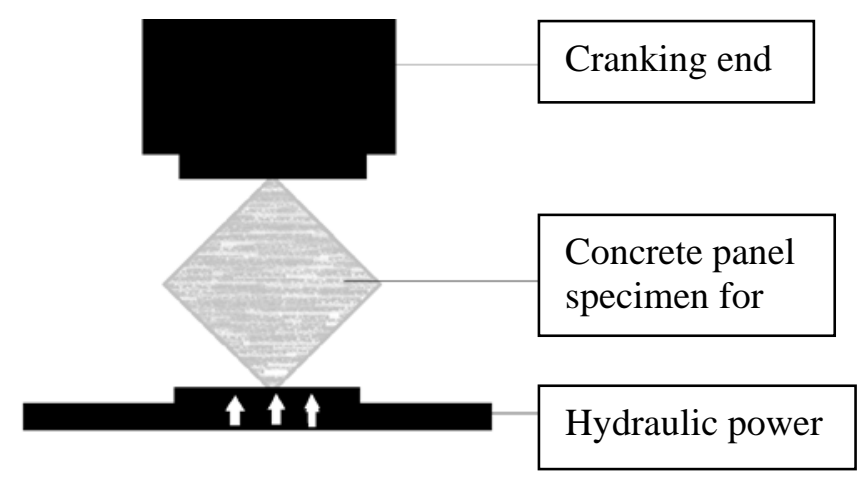

Fig.1 Schematic view of shear testing set-up

\section{Experimental Results and Discussion}

Testing results presented here will be focused on the shear behavior of the HMPE reinforced concrete, which include the shear stress, shear strain and the general shear toughness in terms of shear strain energy corresponding to the length of HMPE fibers applied to the specimens. The results of shear strength test for the concrete reinforced with HMPE fibers are shown in Fig.2, where concrete reinforced with various lengths of HMPE fibers is presented while the volume ratio of fibers to concrete is set constant. It shows that corresponding to the increment of fiber length, a 
decreasing trend in shear strength is observed. The highest strength is $65 \mathrm{~kg} / \mathrm{cm}^{2}$ when the fiber is $20 \mathrm{~mm}$ long. Fig. 3 shows the maximum shear strain, where the largest value appears to the specimen reinforced with second longest fibers, $40 \mathrm{~mm}$. However, compared to the specimen reinforced with $20 \mathrm{~mm}$ fiber, the difference is only $6.5 \%$.

In order to know the overall capacity of the material toughness in terms of the strain energy, the toughness in terms of strain energy calculated from the stress-strain diagram of the testing results is shown in Fig.4. It shows that concrete reinforced with HMPE fibers can have toughness as high as 2.4 times the plain concrete and therefore, the energy needed to break a concrete reinforced with HMPE fibers is 2.4 times than it needed to break a plain concrete. The performance of the specimen with $40 \mathrm{~mm}$ long fibers is slightly better than the one reinforced with $20 \mathrm{~mm}$ long fibers.

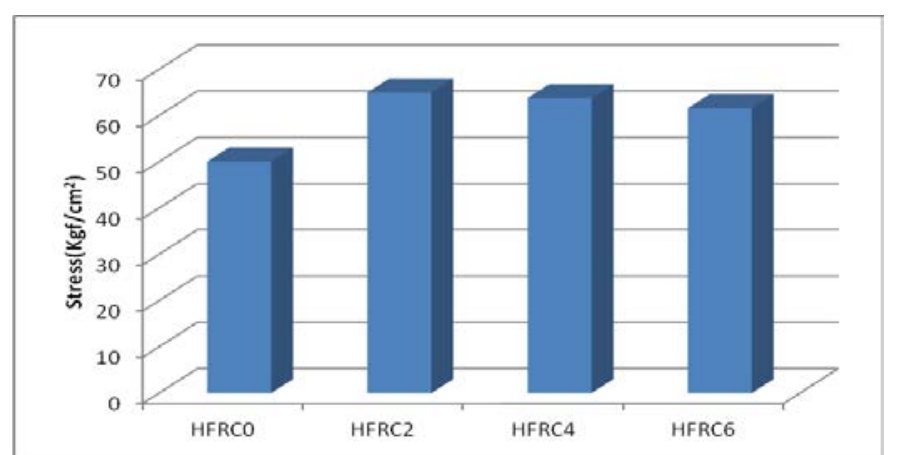

Fig.2 Shear stength corresponding to fiber length

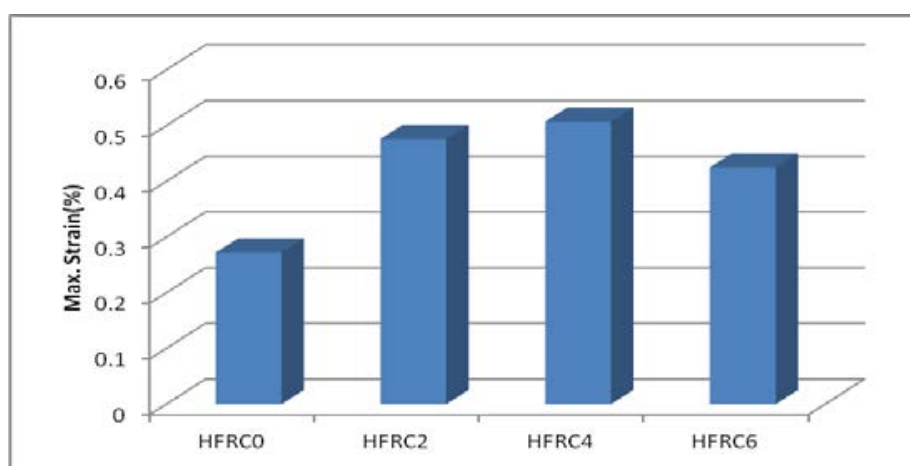

Fig.3 Maximum strain corresponding to fiber length

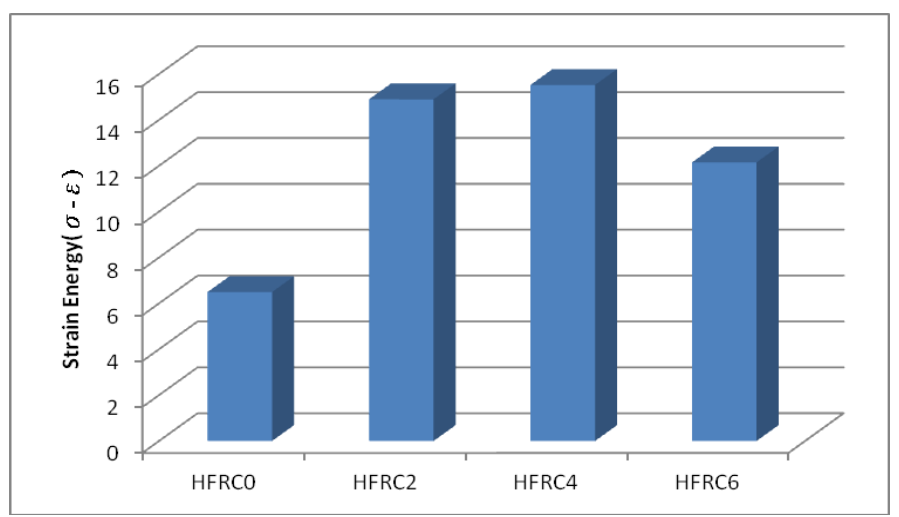

Fig.4 Stress energy during pure shearing test corresponding to fiber length 


\section{Conclusions}

According to the testing results and the corresponding discussions, some valuable conclusions may be drawn as follows.

1) An experimental study for an HMPE fiber reinforced concrete material has been successfully performed for the shear properties.

2) The entrainment of an HMPE fiber material in concrete may effectively enhance its shear strength by $30 \%$ compared to plain concrete.

3) The entrainment of an HMPE fiber material in concrete may effectively enhance its shear strain by $86 \%$ compared to plain concrete.

4) Overall, the shear stress energy evaluated from the stress-strain diagram of the HMPE reinforced concrete material can be increased by 2.4 times compared to plain concrete.

\section{References}

[1] C. D. Atis, O. Karahan, K. Ari, Ö. C. Sola, C. Bilim, Relation between Strength Properties (Flexural and Compressive) and Abrasion Resistance of Fiber (Steel and Polypropylene)-Reinforced Fly Ash Concrete, J Mater Civil Eng 21(8) pp.402 406, 2009.

[2] N Banthia, J.F Trottier, Concrete Reinforced with Deformed Steel Fiber, Part I:Bond-Slip Mechanisms, ACI Materials Journal, September-October, pp.435 446, 1994.

[3] DSM, Performance and application of Dyneema, Hi-Tech Fiber \& Application, Vol.23 No.5, 1998.

[4] N. Hisabe, I. Yoshitake, H. Tanaka, S. Hamada, Mechanical Behavior of Fiber Reinforced Concrete Element Subjected to Pure Shearing Stress, International Workshop on High Performance Fiber Reinforced Cementitious Composites in Structural Applications; 05/2005

[5] A. R. Kalhoo, N. Kim, Mechanical Properties of Normal to High-Strength Steel Fiber-Reinforced Concrete, Cement Concrete Aggregate, Vol.18(2). pp.92 97, 1996.

[6] H. H. Lee, Y.-S. Chen, C.-W. Cheng, Experimental Study on HMPE Fiber Reinforced Concrete, J. Advanced Materials Research, Vol.598(2012), pp.336-340.

[7] G. Velazco, K. Visalvanich, S. P. Shah, Fracture Behavior and Analysis of Fiber Reinforced Concrete Beams, Cement Concrete Research, Vol.10, pp.41 51,1980.

[8] R. J Ward,. V. C Li, Dependent of Flexural Behavior of Fiber Reinforced Mortar on Material Fracture Resistance and Beam Size, ACI Materials Journal, November-December, pp.627-637, 1990. 